Journal of

Synchrotron

Radiation

ISSN 0909-0495

Received 5 May 2011

Accepted 27 July 2011

C 2011 International Union of Crystallography Printed in Singapore - all rights reserved

\section{Increased strontium uptake in trabecular bone of ovariectomized calcium-deficient rats treated with strontium ranelate or strontium chloride}

\author{
Bernhard Pemmer, ${ }^{a}$ Jochen G. Hofstaetter, ${ }^{\text {b,c }}$ Florian Meirer, ${ }^{\text {d,a }}$ Stephan Smolek, \\ Peter Wobrauschek, ${ }^{a}$ Rolf Simon, ${ }^{e}$ Robyn K. Fuchs, ${ }^{f}$ Matthew R. Allen, ${ }^{f}$ \\ Keith W. Condon, ${ }^{f}$ Susan Reinwald, ${ }^{f}$ Roger J. Phipps, ${ }^{\text {g David B. Burr, }}$, $h$ \\ Eleftherios P. Paschalis, ${ }^{b}$ Klaus Klaushofer, ${ }^{b}$ Christina Streli ${ }^{a}$ and Paul Roschger ${ }^{b} *$

\begin{abstract}
aAtominstitut, Technische Universitaet Wien, Stadionallee 2, 1020 Vienna, Austria, ${ }^{\mathbf{b}}$ Ludwig Boltzmann Institute of Osteology at the Hanusch Hospital of WGKK and AUVA Trauma Center Meidling, First Medical Department, Hanusch Hospital, 1140 Vienna, Austria, ' Department of Orthopaedic Surgery, Vienna General Hospital, Medical University of Vienna, Austria, ' ${ }^{\text {MiNALab, }}$ CMM-Irst, Fondazione Bruno Kessler, Via Sommarive 18, 38123 Trento, Italy, e Institute for Synchrotron Radiation, Karlsruhe Institute of Technology, Campus South, 76344 EggensteinLeopoldshafen, Germany, 'Department of Anatomy and Cell Biology, Indiana University School of Medicine, Indianapolis, USA, '⿳H Husson University School of Pharmacy, 1 College Circle, Bangor, ME 04401, USA, and hepartment of Biomedical Engineering, Indiana University-Purdue
\end{abstract} \\ University Indianapolis (IUPUI), Indianapolis, USA. E-mail: paul.roschger@osteologie.at
}

\begin{abstract}
Based on clinical trials showing the efficacy to reduce vertebral and nonvertebral fractures, strontium ranelate $(\mathrm{SrR})$ has been approved in several countries for the treatment of postmenopausal osteoporosis. Hence, it is of special clinical interest to elucidate how the Sr uptake is influenced by dietary $\mathrm{Ca}$ deficiency as well as by the formula of $\mathrm{Sr}$ administration, $\mathrm{SrR}$ versus strontium chloride $\left(\mathrm{SrCl}_{2}\right)$. Three-month-old ovariectomized rats were treated for 90 days with doses of $25 \mathrm{mg} \mathrm{kg}^{-1} \mathrm{~d}^{-1}$ and $150 \mathrm{mg} \mathrm{kg}^{-1} \mathrm{~d}^{-1}$ of $\mathrm{SrR}$ or $\mathrm{SrCl}_{2}$ at low $(0.1 \% \mathrm{Ca})$ or normal $(1.19 \% \mathrm{Ca}) \mathrm{Ca}$ diet. Vertebral bone tissue was analysed by confocal synchrotron-radiation-induced micro X-ray fluorescence and by backscattered electron imaging. Principal component analysis and $k$-means clustering of the acquired elemental maps of $\mathrm{Ca}$ and $\mathrm{Sr}$ revealed that the newly formed bone exhibited the highest $\mathrm{Sr}$ fractions and that low $\mathrm{Ca}$ diet increased the $\mathrm{Sr}$ uptake by a factor of three to four. Furthermore, Sr uptake in bone of the $\mathrm{SrCl}_{2}$-treated animals was generally lower compared with $\mathrm{SrR}$. The study clearly shows that inadequate nutritional calcium intake significantly increases uptake of $\mathrm{Sr}$ in serum as well as in trabecular bone matrix. This indicates that nutritional calcium intake as well as serum Ca levels are important regulators of any Sr treatment.
\end{abstract}

Keywords: strontium ranelate; strontium chloride; dietary calcium; ovariectomized rats; SR $\mu$-XRF; qBEI; elemental mapping; principal component analysis; $k$-means clustering.

\section{Introduction}

Strontium has been studied in the context of a possible therapeutic agent for skeletal diseases for more than half a century (Marie et al., 1985; McCaslin \& Janes, 1959; Shorr \& Carter, 1952; Skoryna, 1981; Storey, 1962; Grynpas \& Marie, 1990). Based on results of recent clinical trials showing reduced vertebral and non-vertebral fracture risk, strontium ranelate (SrR) is now approved in several countries for the treatment of postmenopausal osteoporosis (Reginster et al., 2008). Studies on potential mechanisms for SrR antifracture efficacy include effects on bone microarchitecture and bone re- modeling balance (Ammann et al., 2007; Fuchs et al., 2008a; Ma et al., 2011) and Sr interaction with the calcium-sensing receptor of bone cells (Brennan et al., 2009). Recent studies investigated $\mathrm{Sr}$ accumulation and storage in bone and whether Sr has an impact on the intrinsic material properties of bone (Li et al., 2010; Roschger et al., 2010). It should be emphasized that $\mathrm{Sr}$, with its about two-fold larger atomic weight compared with $\mathrm{Ca}$, interferes with the measurement of bone mineral density (BMD), which is a clinically important surrogate parameter for antifracture effectiveness. Consequently, in Srtreated patients, changes in BMD occur not only due to changes in bone volume and/or mineral content but also due 
Table 1

$\mathrm{Sr}^{2+}$ uptake of bone tissues analysed.

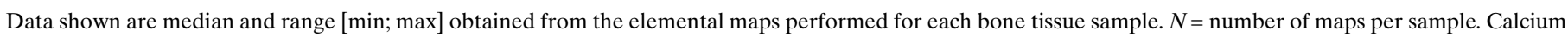

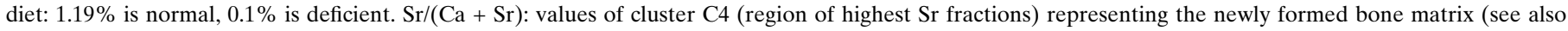

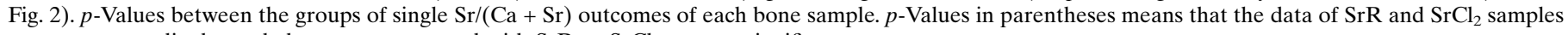
were correspondingly pooled. none: non-treated with $\mathrm{SrR}$ or $\mathrm{SrCl}_{2}$; ns: not significant.

\begin{tabular}{|c|c|c|c|c|c|c|c|}
\hline \multicolumn{4}{|c|}{ Experimental data } & \multicolumn{4}{|c|}{$p$-Values between groups of maps } \\
\hline Sample $(N)$ & $\begin{array}{l}\mathrm{Sr}^{2+} \text { doses } \\
\left(\mathrm{mg} \mathrm{kg}^{-1} \mathrm{~d}^{-1}\right)\end{array}$ & $\begin{array}{l}\text { Ca diet } \\
(\mathrm{wt} \%)\end{array}$ & $\mathrm{Sr} /(\mathrm{Ca}+\mathrm{Sr})$ (count rates) & $\begin{array}{l}\text { Versus } \\
\text { control }\end{array}$ & $\begin{array}{l}\text { Low versus } \\
\text { high } \mathrm{Sr}\end{array}$ & $\begin{array}{l}\text { Deficient versus } \\
\text { normal Ca }\end{array}$ & $\begin{array}{l}\text { SrR versus } \\
\mathrm{SrCl}_{2}\end{array}$ \\
\hline $1 c(3)$ & SHAM none & 1.19 & $0.0012[0.0010 ; 0.0013]$ & & & & \\
\hline $2 c(4)$ & OVX none & 1.19 & $0.0011[0.0011 ; 0.0012]$ & $<0.01$ & & & \\
\hline $3 n(5)$ & SrR 8.5 & 1.19 & $0.024[0.020 ; 0.024]$ & $<0.01$ & & & ns \\
\hline $4 n(4)$ & $\mathrm{SrCl}_{2} 9.4$ & 1.19 & $0.02148[0.018 ; 0.023]$ & $<0.05$ & & $<0.05(<0.001)$ & \\
\hline $5 d(3)$ & SrR 8.5 & 0.1 & 0.1015 [0.094; 0.109] & $<0.01$ & & $<0.05(<0.001)$ & ns \\
\hline $6 d(4)$ & $\mathrm{SrCl}_{2} 9.4$ & 0.1 & $0.085[0.081 ; 0.095]$ & $<0.01$ & $<0.05(<0.001)$ & & \\
\hline $7 n(4)$ & SrR 51 & 1.19 & $0.140[0.136 ; 0.153]$ & $<0.001$ & $<0.01(<0.001)$ & & $<0.05$ \\
\hline $8 n(8)$ & $\mathrm{SrCl}_{2} 56$ & 1.19 & $0.130[0.105 ; 0.138]$ & $<0.05$ & $0.1(<0.001)$ & $0.05(<0.001)$ & \\
\hline $9 d(3)$ & SrR 51 & 0.1 & $0.4252[0.418 ; 0.435]$ & $<0.01$ & $<0.05(<0.001)$ & $<0.01(<0.001)$ & 0.057 \\
\hline $10 d(4)$ & $\mathrm{SrCl}_{2} 56$ & 0.1 & $0.3528[0.322 ; 0.378]$ & & & & \\
\hline
\end{tabular}

to Sr uptake, which makes reliable interpretation of osteodensitometry difficult (Bärenholdt et al., 2009; Blake \& Fogelman, 2007; Kendler et al., 2009). Bearing in mind that, in vertebrates, $99 \%$ of whole body $\mathrm{Ca}$ and $\mathrm{Sr}$ is located in bone (Dahl et al., 2001), the amount incorporated is positively correlated with serum levels of $\mathrm{Sr}$ as numerous studies have shown (Dahl et al., 2001; Fuchs et al., 2008a; Li et al., 2010; Roschger et al., 2010; Boivin et al., 1996; Farlay et al., 2005). In addition, it was recently demonstrated that $\mathrm{Sr}$ is preferentially located in the new bone formed during Sr treatment and only marginally located in the pre-existing bone matrix (Fuchs et al., 2008a; Li et al., 2010; Roschger et al., 2010). Sr atoms are incorporated into the crystal lattice of the bone hydroxyapatite by ionic substitution of calcium ( $\mathrm{Li}$ et al., 2010).

A recent study in ovariectomized (OVX) rats (Fuchs et al., $2008 a)$ determined the effects of high $\left(150 \mathrm{mg} \mathrm{kg}^{-1} \mathrm{~d}^{-1}\right)$ and low $\left(25 \mathrm{mg} \mathrm{kg}^{-1} \mathrm{~d}^{-1}\right.$ ) dose SrR on bone histomorphometric indices, mechanical properties and $\mathrm{Sr}$ uptake. Furthermore, the role of dietary calcium in modulating the effect of SrR on the skeleton was examined by feeding rats either a normal $(1.19 \% \mathrm{Ca})$ or a low calcium diet $(0.1 \% \mathrm{Ca})$. The concentration and distribution of $\mathrm{Ca}$ and $\mathrm{Sr}$ in cortical bone tissue of the tibial midshaft region was determined using a synchrotronradiation-induced micro X-ray fluorescence (SR $\mu$-XRF) method. Animals treated with high-dose SrR had significantly higher $\mathrm{Sr}$ incorporation, regardless of $\mathrm{Ca}$ intake. However, compared with the normal $\mathrm{Ca}$ diet, the low $\mathrm{Ca}$ diet increased the incorporation of Sr into the bone for low- and high-dose SrR groups. All animals treated with $\mathrm{SrR}$ had a higher $\mathrm{Sr}$ fraction at the periosteal bone surface (newly formed bone regions) compared with intracortical bone regions (older bone).

The aim of the present study was to expand these investigations to the administration of $\mathrm{Sr}$ by $\mathrm{SrCl}_{2}$ as well as $\mathrm{SrR}$ with low and normal $\mathrm{Ca}$ diets. A further aim was to extend the analysis for Sr uptake and distribution into the geometrical more complex trabecular bone compartment of the vertebrae, which contains bone marrow, in contrast to tibial periosteal bone. For this purpose, an advanced state-of-the-art confocal
SR $\mu$-XRF technique was used. Quantitative backscattered electron imaging (qBEI) was employed to select regions of interest for SR $\mu$-XRF. In addition, principal component analysis and $k$-means clustering were used to analyze the elemental maps and to separate regions with typical $\mathrm{Sr}$ to $\mathrm{Ca}$ fractions within the samples. This is the first time that such a technique of analysis of elemental maps has been applied to the study of bone tissue.

\section{Methods and materials}

\subsection{Bone samples}

We analyzed bone samples from the previously reported study (Fuchs et al., 2008a) on Sr treatment in three-month-old OVX Sprague-Dawley rats. The animal study was approved by Indiana University's Institutional Animal Care and Use Committee. OVX rats were randomized by body mass three weeks post surgery and divided into eight different treatment regimens: low (25 $\left.\mathrm{mg} \mathrm{kg}^{-1} \mathrm{~d}^{-1}\right)$ and high $\left(150 \mathrm{mg} \mathrm{kg}^{-1} \mathrm{~d}^{-1}\right)$ dose $\mathrm{SrR}$ with low $(0.1 \% \mathrm{Ca})$ and normal $(1.19 \% \mathrm{Ca})$ dietary Ca; low (25 mg kg ${ }^{-1} \mathrm{~d}^{-1}$ ) and high (150 mg kg$\left.{ }^{-1} \mathrm{~d}^{-1}\right) \mathrm{SrCl}_{2}$ with low $(0.1 \% \mathrm{Ca})$ and normal $(1.19 \% \mathrm{Ca})$ dietary $\mathrm{Ca}$. The $\mathrm{Sr}^{2+}$ ion equivalents for $\mathrm{SrR}$ with the chemical formula $\mathrm{C}_{12} \mathrm{H}_{6} \mathrm{~N}_{2} \mathrm{O}_{8} \mathrm{SSr}_{2}\left(513.49 \mathrm{~g} \mathrm{~mol}^{-1}\right)$ were $8.5 \mathrm{mg} \mathrm{kg}^{-1} \mathrm{~d}^{-1}$ and $51 \mathrm{mg} \mathrm{kg}^{-1} \mathrm{~d}^{-1}$, and for $\mathrm{SrCl}_{2}$ with the chemical formula $\mathrm{SrCl}_{2} 6\left(\mathrm{H}_{2} \mathrm{O}\right)\left(266.62 \mathrm{~g} \mathrm{~mol}^{-1}\right)$ were $9.4 \mathrm{mg} \mathrm{kg}^{-1} \mathrm{~d}^{-1}$ and $56 \mathrm{mg}$ $\mathrm{kg}^{-1} \mathrm{~d}^{-1}$, for the low and high $\mathrm{Sr}$ doses, respectively. SHAM operated and untreated OVX rats fed a normal Ca diet served as controls. Animals were treated daily for $90 \mathrm{~d}$. According to previously published Sr serum level data (Fuchs et al., 2008a) the different treatments regimes led to the following mean $\mathrm{Sr}$ serum levels: 22.7 and $23.3 \mathrm{ng} \mathrm{ml}^{-1}$ for untreated SHAM and OVX, 2226.7 and $293.5 \mathrm{ng} \mathrm{ml}^{-1}$ for $25 \mathrm{mg} \mathrm{kg}^{-1} \mathrm{~d}^{-1} \mathrm{SrR}$ treatment at $0.1 \%$ and $1.19 \% \mathrm{Ca}$ diet, respectively, 12611.1 and $1746.0 \mathrm{ng} \mathrm{ml}^{-1}$ for $150 \mathrm{mg} \mathrm{kg}^{-1} \mathrm{~d}^{-1} \mathrm{SrR}$ treatment at $0.1 \%$ and $0.19 \% \mathrm{Ca}$ diet, respectively. One L3 vertebra from each group was used for analysis, while all the measurements of the bone samples were performed blinded to the treatment (Table 1). 
Vertebrae were fixed in $70 \%$ ethanol, dehydrated through a graded series of ethanol, and embedded undecalcified in polymethylmethacrylate (PMMA). About $5 \mathrm{~mm}$-thick blocks containing a sagittal vertebral bone section were obtained using a low-speed diamond saw (Buehler Isomet, Lake Pluff, USA). The section surfaces were ground by sand paper and subsequently polished using a diamond suspension ( 3 and $1 \mu \mathrm{m}$ grain size) on a precision polishing device (PM5 Logitech, Glasgow, Scotland). The sample surface was carbon coated (Agar SEM Carbon Coater, Stansted, UK) prior to qBEI and subsequent SR $\mu-\mathrm{XRF}$ analysis.

\section{2. qBEI}

The intensity of electrons backscattered from the sample surface is proportional to the average atomic number of the target material. For trabecular bone tissue from the rat vertebral bodies, the weight fraction of $\mathrm{Ca}$ (atomic number $Z=$ 20) predominantly influences the material contrast of the bone tissue, which is composed of an organic phase $(Z=6)$ and a hydroxyapatite mineral phase $(Z=14)$. Details of the technique can be found elsewhere (Fratzl-Zelman et al., 2009; Roschger et al., 1998, 2008). qBEI images the local mineral content with a spatial resolution of $<1 \mu \mathrm{m}$. Thus, areas with high backscattered electron intensities, i.e. bright gray levels in the image, represent mineralized matrix with high Ca content, whereas areas with low intensities, i.e. dark gray levels, indicate low Ca content. The method cannot distinguish between a local increase in gray levels caused by $\mathrm{Sr}$ uptake $(Z=38)$ versus $\mathrm{Ca}$. Hence, element-specific methods had to be used to localize and quantify the Sr uptake.

qBEI was performed in a digital scanning electron microscope (DSM 962, Zeiss, Oberkochen, Germany) equipped with a four-quadrant semiconductor backscattered electron detector. The microscope was operated at an acceleration voltage of $20 \mathrm{kV}$, the working distance kept at $15 \mathrm{~mm}$, and the probe current was maintained at $110 \mathrm{pA}$. The entire trabecular bone area was imaged by qBEI using a pixel resolution of $1 \mu \mathrm{m}$. From these qBEI gray-scale images, areas of interest (ROI) have been selected for elemental mapping by confocal SR $\mu$-XRF. The selection criteria were such that the ROI contained trabecular bone features with bone regions (packets) of low and light gray levels representing the coexistence of young and older bone matrix (Fig. 1).

\section{3. $S R \mu-X R F$ analysis}

Micro-XRF is based on the detection of characteristic $\mathrm{X}$-rays induced by high-energy primary photons (Van Grieken \& Markowicz, 2002). Using synchrotron radiation as exciting $\mathrm{X}$-ray source, the outstanding properties of synchrotron radiation, including high photon flux, natural collimation, polarization and the possibility to select the energy of the primary photons, greatly increase the spatial resolution and detection limits (fg-range, $\mu \mathrm{m}$-range) of the $\mu$-XRF. In combination with confocal geometry, high-sensitive element mapping with spatial resolution in the micrometer range can be performed (Zoeger et al., 2006, 2008). More details on confocal SR $\mu$-XRF are provided elsewhere (Zoeger et al., 2006, 2008; Janssens et al., 2004; Kanngießer et al., 2003; Vincze et al., 2004; Simon et al., 2007).

In the present study the confocal SR $\mu$-XRF set-up was installed at the FLUO beamline at ANKA (Karlsruhe, Germany) (Simon et al., 2003). Two polycapillary half lenses with overlapping focal spots were used. The set-up was tested with reference samples revealing a beam size of $10 \mu \mathrm{m} \times$ $10 \mu \mathrm{m}$ and a depth resolution of $12 \mu \mathrm{m}$ at $14.2 \mathrm{keV}(\mathrm{Sr} K \alpha)$. To achieve optimal excitation conditions for $\mathrm{Sr} K$-lines, the excitation energy was adjusted to $17.7 \mathrm{keV}$ by means of a $\mathrm{W} / \mathrm{Si}$ multilayer monochromator. The detector was a $50 \mathrm{~mm}^{2}$ silicon drift detector (Vortex, SII NanoTechnology, USA) connected to a digital signal processor (Saturn, XIA, USA). At a measuring time of $1 \mathrm{~s}$ per spectrum the sensitivity of the method was sufficient for detection of the natural Sr content of bone (about $0.1 \mathrm{wt} \%$ ).

The scans on the sample surface were performed as area scans ranging from $300 \mu \mathrm{m} \times 300 \mu \mathrm{m}$ up to $850 \mu \mathrm{m} \times 850 \mu \mathrm{m}$ depending on the ROI on the sample. For each ROI, several depth scans were performed to determine the correct measurement plane. The optimal depth is where the $\mathrm{Ca} K \alpha$ intensity of the depth scans reaches its maximum. This procedure ensures that the measurement plane is parallel to the sample surface and so all measured voxels are at the same depth within the sample. The acquired spectra were processed using the microxrf 2 software package (B. Vekemans, XMI, Universiteit Gent) installed at the beamline to generate the elemental maps. Peak deconvolution and subtraction of the spectral background was carried out with the AXIL (Van Espen et al., 1986) module implemented in this package. The resulting maps of net intensities were normalized to counts per second and $100 \mathrm{~mA}$ storage ring current, and were converted to 8-bit grayscale images.

\subsection{Principal component analysis and $\boldsymbol{k}$-means clustering}

Owing to the large number of maps (up to eight scans per sample and ten samples resulting in a total of 42 scans), an automated image data analysis technique was used to extract the typical $\mathrm{Sr}$ to $\mathrm{Ca} K \alpha$-lines counts fractions of the bone areas. This method was originally established and described by Vekemans et al. (1997). Like all other clustering methods $k$-means clustering (KMC) allows calculation of the degree of similarity (or distance in property space) between two objects to be clustered. In the presented case the objects are pixels (index $i$ ) and their properties are either X-ray intensities derived from the spectrum of pixel $i$ or the score values of that pixel on the equivalent principal component axes. The similarity measure between two pixels $A$ and $B$ can then be expressed as Euclidian distance in property space. The result of such a clustering (after principal component pre-treatment) is displayed in Fig. 2. The pre-treatment using principal component analysis (PCA) is not indispensable but allows for more rapid processing of the data set by eliminating noise and reducing dimensionality prior to the clustering (e.g. if more than two pixel properties, here X-ray intensities of specific 
(a) $\mathrm{BE}$

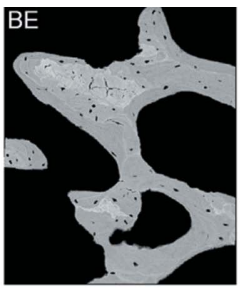

(b)

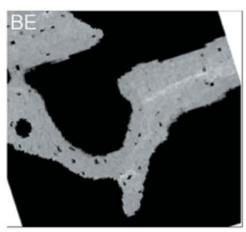

(c) $\mathrm{BE}$

(d) $\mathrm{BE}$

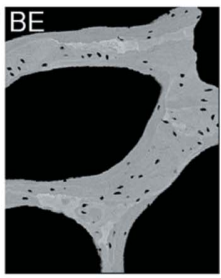

(e)

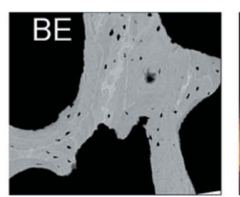

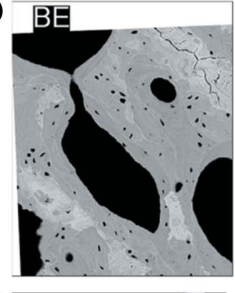
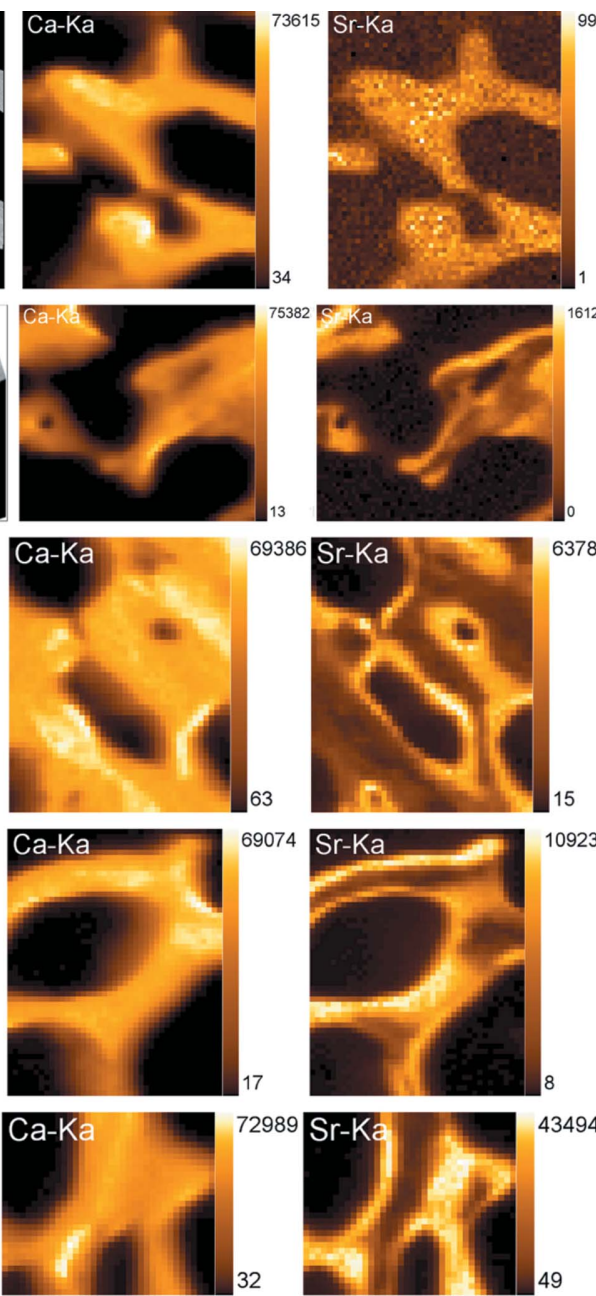

Figure 1

Examples of qBEI images and the corresponding SR $\mu$-XRF elemental maps of calcium (Ca) and strontium ( $\mathrm{Sr}$ ) based on $\mathrm{Ca} K \alpha$ and $\mathrm{Sr} K \alpha$ fluorescence lines, respectively, from bone samples of animals untreated and treated by $\mathrm{SrR}_{\text {or }} \mathrm{SrCl}_{2}$ : (a) untreated, $(b)$ low $\mathrm{Sr}$ dose at normal $\mathrm{Ca}$ diet, $(c)$ low Sr dose at deficient Ca diet, $(d)$ high Sr dose at normal Ca, and (e) high Sr dose at deficient $\mathrm{Ca}$. The pixel size of the SR $\mu$-XRF elemental maps is $10 \mu \mathrm{m} \times 10 \mu \mathrm{m}$ with a depth resolution of $12 \mu \mathrm{m}$ at $\mathrm{Sr}$ $K \alpha(14.2 \mathrm{keV})$. The color-coded X-ray intensities (counts $\mathrm{s}^{-1}$ ) are scaled from minimum to maximum. qBEI shows young bone packets (less mineralized) as darker, and older bone packets as well as residual cartilage (higher mineralized) as brighter gray levels.

elements, are investigated). The clustering algorithm could also be applied to the X-ray maps directly; however, in this case only images should be used showing high contrasts (low noise) which are appropriately scaled to each other. The approach using PCA to pre-process the data before KMC takes care of the image selection (noise removal) and scaling problem.

A number of four clusters proved to be sufficient for proper $\mathrm{KMC}$ results, as more than four clusters led to empty clusters in the result. PCA and $\mathrm{KMC}$ were performed for all samples. The classification of the clusters $\mathrm{C} 1, \mathrm{C} 2, \mathrm{C} 3, \mathrm{C} 4$ was performed by considering their $\mathrm{Sr}$ counts fraction values $[\mathrm{Sr} /(\mathrm{Sr}+\mathrm{Ca})]$ (Fig. 2). The median and range [min; max] (Table 1) of the $\mathrm{Sr}$ to $\mathrm{Ca}$ counts fraction values of cluster $\mathrm{C} 4$ from the individual elemental maps per bone tissue sample was determined.

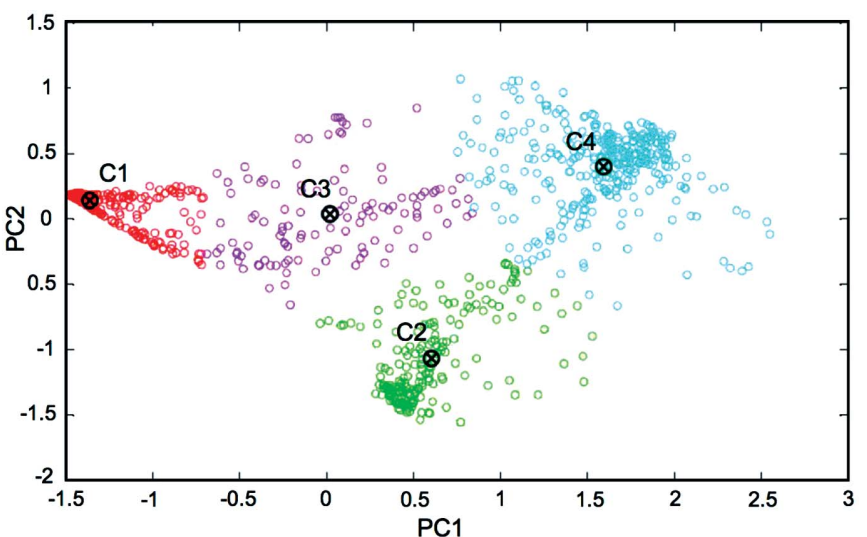

(a)
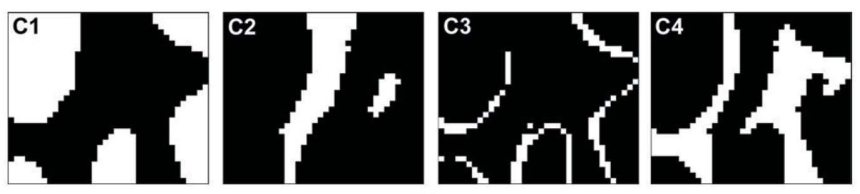

(b)

\section{Figure 2}

Example of a PCA + KMC analysis. The scan was performed on a sample ( $9 d$ of Table 1) with high-dose SrR treatment at deficient Ca diet. (a) Score plot of principle components PC1 versus PC2 derived from a plot of Ca versus Sr intensities by linear transformation exhibiting a new set of mutually orthogonal axes. The PC1 axis represents the direction of constant $\mathrm{Sr} / \mathrm{Ca}$ ratios. The PC2 axis represents the direction of changing $\mathrm{Sr} / \mathrm{Ca}$ ratios. The KMC analysis of the PCA score plot used four clusters $(k=4)$, color-coded red, green, pink and blue; the crosses in circles are centroids of clusters $\mathrm{C} 1, \mathrm{C} 2, \mathrm{C} 3, \mathrm{C} 4$. The meaning of the clusters can be explained by generating binary images, where all pixels corresponding to a certain cluster are displayed in white $(b)$. $(b)$ Binary images produced according to the cluster data: image $\mathrm{C} 1$ shows the distribution of pixels clustered in $\mathrm{C} 1$ (red) and corresponds to the background/bone-marrow space, where both $\mathrm{Ca}$ and $\mathrm{Sr}$ concentrations are zero. Image $\mathrm{C} 2$ (pixels from cluster $\mathrm{C} 2$, green) highlights areas of old bone showing a low $\mathrm{Sr}$ to $\mathrm{Ca}$ fraction, while image $\mathrm{C} 3$ (pixels clustered in $\mathrm{C} 3$, purple) contains pixels representing the rim region of the bone. Finally, image $\mathrm{C} 4$, which contains all pixels of cluster C4 (cyan), displays pixels of highest $\mathrm{Sr}$ to $\mathrm{Ca}$ fraction, corresponding to areas of young bone.

Cluster C4 was the region of highest $\mathrm{Sr}$ counts fractions representing the newly formed bone matrix (Fig. 2). MannWhitney tests between the groups of single $\mathrm{Sr} /(\mathrm{Ca}+\mathrm{Sr})$ outcomes from each bone sample were performed to determine the significance levels ( $p$-values) of the differences. A value of $p<0.05$ was considered as significant. Additionally, the significance of differences between low and high $\mathrm{Sr}$ doses or deficient and normal $\mathrm{Ca}$ content were also evaluated independently for type of administration $\left(\mathrm{SrR}\right.$ and $\left.\mathrm{SrCl}_{2}\right)$. In these cases the outcomes of $\mathrm{SrR}$ and $\mathrm{SrCl}_{2}$ samples were correspondingly pooled (Table 1 ).

\section{Results}

Sr levels were measured in vertebral trabecular bone in rats treated with low- and high-dose $\mathrm{SrR}$ and $\mathrm{SrCl}_{2}$ with normal and low $\mathrm{Ca}$ diet, and in untreated controls. Based on qBEI images, areas containing newly formed bone were selected for confocal SR $\mu$-XRF. Examples of maps (Ca, Sr and corresponding qBEI) for five treatment groups are shown in Fig. 1. 
Comparing the elemental maps of $\mathrm{Sr}$ with the corresponding qBEI images revealed that, with $\mathrm{Sr}$ administration, $\mathrm{Sr}$ was mainly incorporated into the newly formed bone matrix predominantly adjacent to the bone surface (darker graylevels in qBEI), and was marginally incorporated into the old higher mineralized bone packets (brighter gray-levels in the qBEI images). Untreated controls (Fig. 1a) showed a homogeneous $\mathrm{Sr}$ distribution of natural $\mathrm{Sr}$, with the lowest level of $\mathrm{Sr}$ count rates. This indicates that, with natural intake over time, $\mathrm{Sr}$ was associated with all the bone packets equally.

Considering the maximum of $\mathrm{Sr}$ count rates in the Sr maps as indicated by color-coded intensity scales (Fig. 1a-1e), bone samples from different $\mathrm{Sr}$ treatment regimes show $\mathrm{Sr}$ count rates ascending from low $\mathrm{Sr}$ dose with normal $\mathrm{Ca}$ diet followed by low $\mathrm{Sr}$ with low $\mathrm{Ca}$ diet, high $\mathrm{Sr}$ dose with normal $\mathrm{Ca}$ diet, and finally by high $\mathrm{Sr}$ dose with low Ca diet.

PCA and KMC of the elemental maps (Fig. 2a) assigned all samples consistently into the ten different treatments. The cluster (C4) with the highest $\mathrm{Sr}$ counts fraction $\mathrm{Sr} /(\mathrm{Ca}+\mathrm{Sr})$ values representing the newly formed bone was used for the assignment, because it showed the largest differences between the treatment groups (Fig. $2 b$ ). The $\mathrm{C} 4$ outcomes are shown in Table 1. The increase in the $\mathrm{Sr}$ to Ca counts fraction with normal Ca diet was 20.8 times for low SrR doses and 121.7 times for high SrR doses compared with untreated animals. Low $\mathrm{Ca}$ diet additionally increased the $\mathrm{Sr}$ counts fraction 89 times for low SrR dose and 365 times for high SrR dose compared with normal Ca diet. In Fig. 3 the effect of low $\mathrm{Ca}$ diet on $\mathrm{Sr}$ uptake is clearly demonstrated. Further, the direct relationship between increase in $\mathrm{Sr}$ uptake and that of $\mathrm{Sr}$ serum levels can be seen.

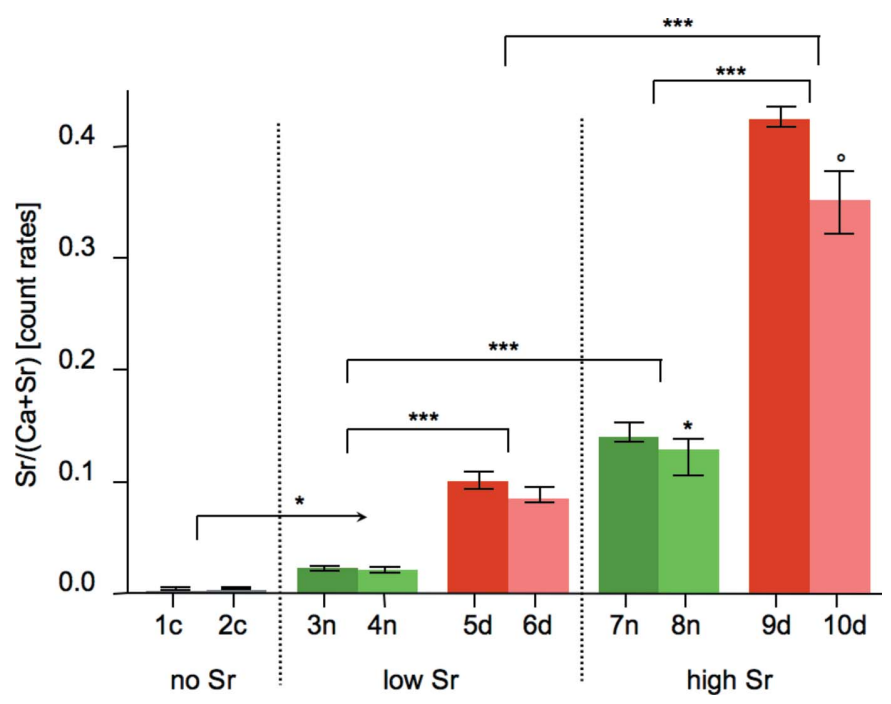

Figure 3

Influence of $\mathrm{Ca}$ diet on $\mathrm{Sr}$ uptake as quantified by cluster $\mathrm{C} 4$ centroid values indicated by green (normal $\mathrm{Ca}$ diet) and red bars (deficient $\mathrm{Ca}$ diet), respectively, whereby differences between $\mathrm{SrR}$ and $\mathrm{SrCl}_{2}$ are distinguished by intense and light color. The increase in Sr uptake (height of the bars) was in parallel with the increase in $\mathrm{Sr}$ serum levels. For each sample, median and range (error bars) resulting from all maps recorded are indicated. Significance levels as obtained by Mann-Whitney tests: $* p<0.05$. *** $p<0.001{ }^{\circ} p=0.057$.
Sr uptake in cluster $\mathrm{C} 4$ for low $\mathrm{Sr}$ dose and high $\mathrm{Sr}$ dose was lower for $\mathrm{SrCl}_{2}$ versus $\mathrm{SrR}(-7.7 \%$ and $-9.1 \%$, respectively, with normal Ca diet; $-20.4 \%$ and $-19.8 \%$, respectively, with low $\mathrm{Ca}$ diet), but differences were only partly significant (Table 1).

\section{Discussion}

In this analysis $\mathrm{SR} \mu$-XRF combined with $\mathrm{qBEI}$ together with PCA and KMC were used to evaluate Sr uptake into bone with different levels of Sr intake and dietary $\mathrm{Ca}$ intake. Analysis of the $\mathrm{Sr}$ to $\mathrm{Ca}$ fractions showed that $\mathrm{Sr}$ uptake in newly formed bone increases with increasing $\mathrm{Sr}$ dose. Low dietary Ca further elevated Sr uptake. Sr uptake in bone was slightly higher with $\mathrm{SrR}$ compared with $\mathrm{SrCl}_{2}$ even though the $\mathrm{Sr}^{2+}$ equivalent in $\mathrm{SrCl}_{2}$ was $10 \%$ higher than in $\mathrm{SrR}$.

This is the first time that PCA and KMC have been applied to elemental maps from bone tissue to identify regions of characteristic elemental fractions. An advantage of this method is that it is mathematically objective and cannot be biased by interaction with the observer. Also the observer needs no specialized knowledge on the microscopic appearance of the elemental maps. As a result this procedure is fast, can handle a large number of maps, and can be expanded to investigate relations among more than two elements. The present analysis of the bone tissue regions with a maximum in Sr to Ca counts fraction consistently and correctly identified tissue from non-treated and from all animals treated differently with the eight combinations of $\mathrm{Sr}$ treatment and dietary Ca.

\subsection{Ca diet versus Sr uptake}

Low Ca significantly increased (three to four times, Table 1) the $\mathrm{Sr}$ to $\mathrm{Ca}$ counts fraction in the $\mathrm{C} 4$ cluster identified by qBEI imaging as newly formed bone, i.e. regions with low $\mathrm{Ca}$ content predominantly at the bone surface. In this context it is interesting how the serum levels were influenced by dietary $\mathrm{Ca}$, because the serum level of $\mathrm{Sr}$ determines how much $\mathrm{Sr}$ is incorporated in the HA lattice during bone formation ( $\mathrm{Li}$ et al. , 2010; Roschger et al., 2010). As previously reported (Fuchs et al., 2008a), these rats treated with 25 or $150 \mathrm{mg} \mathrm{kg}^{-1} \mathrm{~d}^{-1}$ of $\mathrm{SrR}$ and fed the low calcium diet $(0.1 \% \mathrm{Ca})$ showed increases of more than seven times in serum Sr levels compared with rats fed the normal calcium diet $(1.19 \% \mathrm{Ca})$. Such an effect of nutritional Ca deficiency might be of importance concerning safety issues of $\mathrm{Sr}$ treatment in patients with osteoporosis. Normal serum $\mathrm{Ca}$ levels, and adequate $\mathrm{Ca}$ and vitamin $\mathrm{D}$ intake, must be a prerequisite of any osteoporosis treatment. Low serum Ca levels would result in higher uptake of $\mathrm{Sr}$, which can induce osteomalacia and mineralization defects (Storey, 1962; Omdahl \& DeLuca, 1971; Sobel et al., 1935).

\section{2. $\mathrm{SrR}$ versus $\mathrm{SrCl}_{2}$}

We also compared Sr uptake in bone with administration of two different forms of $\mathrm{Sr}\left(\mathrm{SrR}\right.$ and $\left.\mathrm{SrCl}_{2}\right)$. At both $\mathrm{Sr}^{2+}$ doses, low and high, the $\mathrm{Sr}$ uptake in the new bone matrix was higher 
with $\mathrm{SrR}$ compared with $\mathrm{SrCl}_{2}$, even though the $\mathrm{Sr}^{2+}$ equivalent with $\mathrm{SrCl}_{2}$ was $10 \%$ higher than with $\mathrm{SrR}$. For the normal Ca diet it was about $8 \%$ higher, while for the low Ca diet it was $20 \%$ higher. The results suggest that, when Sr treatment occurs at normal dietary $\mathrm{Ca}$ levels, $\mathrm{SrR}$ promotes greater uptake to bone compared with $\mathrm{SrCl}_{2}$. However, care has to be taken for adequate $\mathrm{Ca}$ serum levels, because $\mathrm{SrR}$ might deliver too much $\mathrm{Sr}$ into the serum in the case of Ca deficiency.

\subsection{Limitations}

The study was designed as a pilot study for testing the sensitivity to detect spatially resolved $\mathrm{Sr}$ in bone after different Sr treatment regimes using a special confocal SR $\mu$ XRF set-up. For this purpose we analyzed just one vertebral bone sample per group from ten groups; two from untreated animals (SHAM and OVX) and eight from animals of different treatment regimens (low and high $\mathrm{Sr}$ as $\mathrm{SrR}$ or $\mathrm{SrCl}_{2}$ combined with normal or low dietary $\mathrm{Ca}$ ). However, the consistency in relationship between sample outcome and treatment regime, as well as agreement with the previous analysis of the tibial/periosteal bone ( $n=10$ per group) (Fuchs et al., 2008a), suggests that the one tissue/group analyzed in this study was representative of its treatment group. Although several numerical differences were large, many were not statistically significant. This is likely to be due to the limited number of scans per bone tissue (in majority three to four scans).

Another limitation is that the reported $\mathrm{Sr}$ and $\mathrm{Ca}$ concentrations are not given in absolute values (wt\%), but always in fractions of Sr to Ca X-ray peak count rates. Unfortunately, there are no suitable reference standards for this novel experimental set-up that would have allowed calculation of absolute $\mathrm{Sr}$ and $\mathrm{Ca}$ concentrations from the $\mathrm{X}$-ray count rates. Differences in sensitivity of the system to detect $\mathrm{Ca}$ and $\mathrm{Sr}$, and differences in matrix effects between $\mathrm{Ca} K \alpha$ and $\mathrm{Sr} K \alpha$ $\mathrm{X}$-rays make it difficult to generate suitable reference standards.

$\mathrm{Sr}$ serum concentrations in this study were lower or encompassed levels (12611 $\mathrm{ng} \mathrm{ml}^{-1}$, or $185 \mu \mathrm{mol} \mathrm{\textrm {L } ^ { - 1 }}$ ) comparable with those produced by SrR treatment of postmenopausal osteoporosis $\left(10560 \mathrm{ng} \mathrm{ml}^{-1}\right.$, or $120.4 \mu \mathrm{mol} \mathrm{L}{ }^{-1}$ ) (Roschger et al., 2010; Fuchs et al., 2008b). In this human study an atomic fraction for $\mathrm{Sr}$ to $\mathrm{Ca}$ of $5 \%$ was found (Roschger $e t$ al., 2010; Li et al., 2010), but extrapolation from animals to humans and vice versa should be made with caution.

\section{Conclusions}

In conclusion, dietary and serum levels of $\mathrm{Ca}$ are important determinants of serum Sr levels and Sr uptake into bone with SrR treatment for osteoporosis. To avoid higher uptake rates of $\mathrm{Sr}$ and improve safety in patients being treated with $\mathrm{SrR}$, adequate $\mathrm{Ca}$ and vitamin $\mathrm{D}$ intake is essential.

This work was supported by the European Community Research Infrastructure Action under the FP6 'Structuring the European Research Area' ['Integrating Activity on Synchro- tron and Free Electron Laser Science' (IA-SFS) RII3-CT2004-506008], by the AUVA (Austrian Workers' Compensation Board), the WGKK (Vienna Health Insurance Fund), and a research grant from the Alliance for Better Bone Health. Further we thank G. Dinst, S. Thon, Ph. Messmer and D. Gabriel for careful sample preparations, and qBEI and EDX measurements.

\section{References}

Ammann, P., Badoud, I., Barraud, S., Dayer, R. \& Rizzoli, R. (2007). J. Bone Miner. Res. 22, 1419-1425.

Bärenholdt, O., Kolthoff, N. \& Nielsen, S. P. (2009). Bone, 45, 200206.

Blake, G. M. \& Fogelman, I. (2007). J. Clin. Densitom. 10, 259265.

Boivin, G., Deloffre, P., Perrat, B., Panczer, G., Boudeulle, M., Mauras, Y., Allain, P., Tsouderos, Y. \& Meunier, P. J. (1996). J. Bone Miner. Res. 11, 1302-1311.

Brennan, T. C., Rybchyn, M. S., Green, W., Atwa, S., Conigrave, A. D. \& Mason, R. S. (2009). Br. J. Pharmacol. 157, 1291-1300.

Dahl, S. G., Allain, P., Marie, P. J., Mauras, Y., Boivin, G., Ammann, P., Tsouderos, Y., Delmas, P. D. \& Christiansen, C. (2001). Bone, 28, 446-453.

Farlay, D., Boivin, G., Panczer, G., Lalande, A. \& Meunier, P. J. (2005). J. Bone Miner. Res. 20, 1569-1578.

Fratzl-Zelman, N., Roschger, P., Gourrier, A., Weber, M., Misof, B. M., Loveridge, N., Reeve, J., Klaushofer, K. \& Fratzl, P. (2009). Calcif. Tissue Intl, 85, 335-343.

Fuchs, R. K., Allen, M. R., Condon, K. W., Reinwald, S., Miller, L. M., McClenathan, D., Keck, B., Phipps, R. J. \& Burr, D. B. (2008a). Osteoporosis Intl, 19, 1331-1341.

Fuchs, R. K., Allen, M. R., Condon, K. W., Reinwald, S., Miller, L. M., McClenathan, D., Keck, B., Phipps, R. J. \& Burr, D. B. (2008b). Osteoporosis Intl, 19, 1815-1817.

Grynpas, M. D. \& Marie, P. J. (1990). Bone, 11, 313-319.

Janssens, K., Proost, K. \& Falkenberg, G. (2004). Spectrochim. Acta B, 59, 1637-1645.

Kanngießer, B., Malzer, W. \& Reiche, I. (2003). Nucl. Instrum. Methods Phys. Res. B, 211, 259-264.

Kendler, D. L., Adachi, J. D., Josse, R. G. \& Slosman, D. O. (2009). Osteoporosis Intl, 20, 1101-1106.

Li, C., Paris, O., Siegel, S., Roschger, P., Paschalis, E. P., Klaushofer, K. \& Fratzl, P. (2010). J. Bone Miner. Res. 25, 968-975.

Ma, Y. L., Zeng, Q. Q., Porras, L. L., Harvey, A., Moore, T. L., Shelbourn, T. L., Dalsky, G. P., Wronski, T. J., Aguirre, J. I., Bryant, H. U. \& Sato, M. (2011). Endocrinology, 152, 1767-1778.

McCaslin, F. \& Janes, J. (1959). Proc. Mayo Clin. 34, 329-334.

Marie, P. J., Garba, M. T., Hott, M. \& Miravet, L. (1985). Miner. Electrolyte Metab. 11, 5-13.

Omdahl, J. L. \& DeLuca, H. F. (1971). Science, 174, 949-951.

Reginster, J. Y., Felsenberg, D., Boonen, S., Diez-Perez, A., Rizzoli, R., Brandi, M. L., Spector, T. D., Brixen, K., Goemaere, S., Cormier, C., Balogh, A., Delmas, P. D. \& Meunier, P. J. (2008). Arthritis Rheum. 58, 1687-1695.

Roschger, P., Fratzl, P., Eschberger, J. \& Klaushofer, K. (1998). Bone, 23, 319-326.

Roschger, P., Manjubala, I., Zoeger, N., Meirer, F., Simon, R., Li, C., Fratzl-Zelman, N., Misof, B. M., Paschalis, E. P., Streli, C., Fratzl, P. \& Klaushofer, K. (2010). J. Bone Miner. Res. 25, 891-900.

Roschger, P., Paschalis, E. P., Fratzl, P. \& Klaushofer, K. (2008). Bone, 42, 456-466.

Shorr, E. \& Carter, A. C. (1952). Bull. Hosp. Joint Dis. 13, 59-66.

Simon, R., Buth, G. \& Hagelstein, M. (2003). Nucl. Instrum. Methods Phys. Res. B, 199, 554-558.

Simon, R., Kerdpin, U., Friedrich, F., Faubel, W., Weidler, P. G. \& Nüesch, R. (2007). Adv. X-ray Anal. 50, 64-70. 
Skoryna, S. C. (1981). Can. Med. Assoc. J. 125, 703-712.

Sobel, A. E., Cohen, J. \& Kramer, B. (1935). Biochem. J. 29, 26402645.

Storey, E. (1962). J. Bone Joint Surg. Br. 44B, 194-208.

Van Espen, P., Janssens, K. \& Nobels, J. (1986). Chemometr. Intell. Lab. Syst. 1, 109-114.

Van Grieken, R. \& Markowicz, A. (2002). Handbook of X-ray Spectrometry, 2nd ed. New York: Marcel Dekker.

Vekemans, B., Janssens, K., Vincze, L., Aerts, A., Adams, F. \& Hertogen, J. (1997). X-ray Spectrom. 26, 333-346.
Vincze, L., Vekemans, B., Brenker, F. E., Falkenberg, G., Rickers, K., Somogyi, A., Kersten, M. \& Adams, F. (2004). Anal. Chem. 76, 6786-6791.

Zoeger, N., Roschger, P., Hofstaetter, J. G., Jokubonis, C., Pepponi, G., Falkenberg, G., Fratzl, P., Berzlanovich, A., Osterode, W., Streli, C. \& Wobrauschek, P. (2006). Osteoarthritis Cartilage, 14, 906-913. Zoeger, N., Streli, C., Wobrauschek, P., Jokubonis, C., Pepponi, G., Roschger, P., Hofstaetter, J., Berzianovich, A., Wegrzynek, D., Chinea-Cano, E., Markowicz, A., Simon, R. \& Falkenberg, G. (2008). X-ray Spectrom. 37, 3-11. 